Article

\title{
@Shakespeare and @TwasFletcher: Performances of Authority
}

\author{
Nora J. Williams \\ Independent Scholar, Bristol, UK; nora.j.williams@gmail.com
}

Received: 4 February 2019; Accepted: 23 February 2019; Published: 4 March 2019

\begin{abstract}
Shakespeare: Trying to keep incognito with \#WSCongress16 in town. If a scholar sees me I just say, "Hullo, lovely to meet you. I'm Peter Holland" /@TwasFletcher: Tell them you're Me!' (1 August 2016). This article looks at the anonymously-managed @Shakespeare account and its performance of Shakespeare's authority on social media, in the context of the parody bot account @TwasFletcher. I argue that authority is established and performed by @Shakespeare through interaction with other authoritative accounts, literary in-jokes, engagement with academic conferences, and, most crucially, anonymity. The destabilising or undermining of Shakespeare's online authority as performed by @TwasFletcher, is especially significant for its lack of anonymity: created by Hofstra University professor and associate dean Vimala C. Pasupathi, @TwasFletcher raises questions about how scholars who are not white, cis-het men make space for themselves within the authority commanded by Shakespeare, especially online. By inserting Fletcher into Shakespeare, Pasupathi herself performs authority in opposition to Shakespeare and the dominant idea of who a Shakespeare scholar should be or what s/he should do. This essay will therefore argue that two meanings of "authority" — recognized as true or valid on the one hand, and domineering, autocratic, or imposing on the other-play out through the relationship between @Shakespeare and @TwasFletcher on Twitter.
\end{abstract}

Keywords: Shakespeare; digital humanities; digital culture; Twitter; social media; authority

\section{Introduction}

Twitter represents part of what Stephen O'Neill calls 'a surfeit of Shakespeares' (O'Neill 2018, p. 121) in the digital age, offering us a smorgasbord of adaptations, appropriations, avatars, re-imaginings, and transformations with which to engage. All of these Shakespeares deploy his cultural authority differently, but the shared understanding that Shakespeare's authority is there to be assumed (or, at least, something with which any user can collaborate) remains constant across the various iterations of Shakespeare's 'digital ghost' (Rosvally 2017). Launched in 2006 and now hosting, on average, over 6000 tweets per second ('Twitter Usage Statistics' 2019), Twitter is a microblogging social network that limits user-generated posts (or "tweets") to 280 characters each. ${ }^{1}$ Users can also "retweet" or "quote tweet" posts from other users, and as the platform has gained popularity, developers have added additional multimedia functions, such as embedded photos and GIFs, polls, location tags, and live video. ${ }^{2}$ Crucially for my purposes, each Twitter user chooses a handle, beginning with "@", through which they are identified on the platform; this handle need not be associated with the user's

\footnotetext{
From its founding until 2017, Twitter limited each "tweet" to 140 characters.

For more complete introductions to Twitter and its affordances, see Murthy (2013), Twitter: Social Communication in the Twitter Age, Cambridge: CUP; Calbi (2013), "He Speaks ... Or Rather ... He Tweets": The Specter of the "Original," Media, and "Media-Crossed" Love in Such Tweet Sorrow. In Spectral Shakespeares: Media Adaptations in the Twenty-First Century. New York: Palgrave Macmillan, pp. 137-62; and Mullin (2018), 'Tweeting Television/Broadcasting the Bard: @HollowCrownFans
} 
real name (as on Facebook) and therefore certain accounts take on the personae of long-dead celebrities, authors, and other public figures.

In this article, I consider two interactions with the phastasmic presence of Shakespeare on Twitter: @Shakespeare and @TwasFletcher. Tweeting since 2010, @Shakespeare is a handle managed by persons known only as 'ghost tweeters' who effectively —and, often, metatheatrically - maintain the fiction that Shakespeare himself is undead in the twenty-first century. As described by O'Neill, @Shakespeare is one of many 'digital iterations of Shakespeare's uncanny temporality, or the textual assemblage that is Shakespeare's status as the living-dead, a machine-like thing that keeps going on and on' (O'Neill 2018, p. 122). @TwasFletcher, on the other hand, is a bot-based experiment conducted by Vimala Pastupathi with the intention of testing what it would 'look like' to 'replace Shakespeare with Fletcher, if only in digital spaces' (Pasupathi 2015). @TwasFletcher therefore represents an interruption—or, perhaps, as Emma Smith has argued, an ironic re-inscription—of Shakespeare's authority (Smith 2017). Both accounts, however, conjure the ghostly presences of their namesakes-@Shakespeare consistently, and @TwasFletcher only occasionally-in order to manipulate that authority.

This article activates two definitions of 'authority' in an effort to parse the relationships between Shakespeare, Fletcher, @Shakespeare, @TwasFletcher, the 'ghost tweeters', and Pasupathi. These are: 'authority' in the sense of truth, validity, and reliability (authorised, authoritative), and 'authority' in the sense of power, control, and enforcement (authoritarian). Authenticity is, of course, a fraught concept for Shakespeareans: the so-called authorship controversy continues to attract followers, in the professional theatre if not in academia, while at the same time reviews of Shakespearean productions still measure success in terms of fidelity to Shakespeare's "original"3. The issue of fidelity to an original as a marker of authenticity and authority is still as live today-despite the 'convergence culture' (Jenkins 2006) of social media—as when Walter Benjamin argued that

[t]he here and now of the original underlies the concept of its authenticity [ $\ldots$ ] The whole sphere of authenticity eludes technological-and of course not only technological-reproduction. But whereas the authentic work retains its full authority in the face of a reproduction made by hand, which it generally brands a forgery, this is not the case with technological reproduction. (Benjamin 2002, p. 103)

Although the relationship between the 'original' and the 'reproduction' is already complex in the case of Shakespeare, these complications are intensified by digital technologies and their advanced reproductive capabilities. In the swirl of the assemblages that (re)animate Shakespeare's legacy, we can no longer say with confidence what is original and what is reproduced —or reincarnated. In playing around with death and animation, I also pick up Danielle Rosvally's identification of @Shakespeare as a 'digital ghost'; in engaging with and extending Rosvally's terminology, I also engage with the longer critical history of literary and dramatic 'ghosting', including the the work of Benjamin, Jacques Derrida, Marjorie Garber, Herbert Blau, and Marvin Carlson on the afterlives of art (and specifically performances) as processual 'hauntings' that continuously carry forward into the present (Rosvally 2017).

\section{2. 'Tell Them You're Me!' Ghostly Identities on Twitter}

With these contexts in mind, I want to frame my engagement with @Shakespeare and $@$ TwasFletcher through this tweet exchange (Figure 1):

and Digital Shakespeares'. In Broadcast Your Shakespeare: Continuity and Change Across Media. Edited by Stephen O'Neill. London: Bloomsbury Arden, pp. 207-26.

3 Mark Rylance, former Artistic Director of Shakespeare's Globe, recently wrote to Foreword to a forthcoming book by Barry R. Clarke on Francis Bacon's Contribution to Shakespeare: A New Attribution Method (Clarke 2019). See Kidnie (2009), Shakespeare and the Problem of Adaptation for a more complete discussion of the role of 'authenticity' in reviews of Shakespeare productions. 


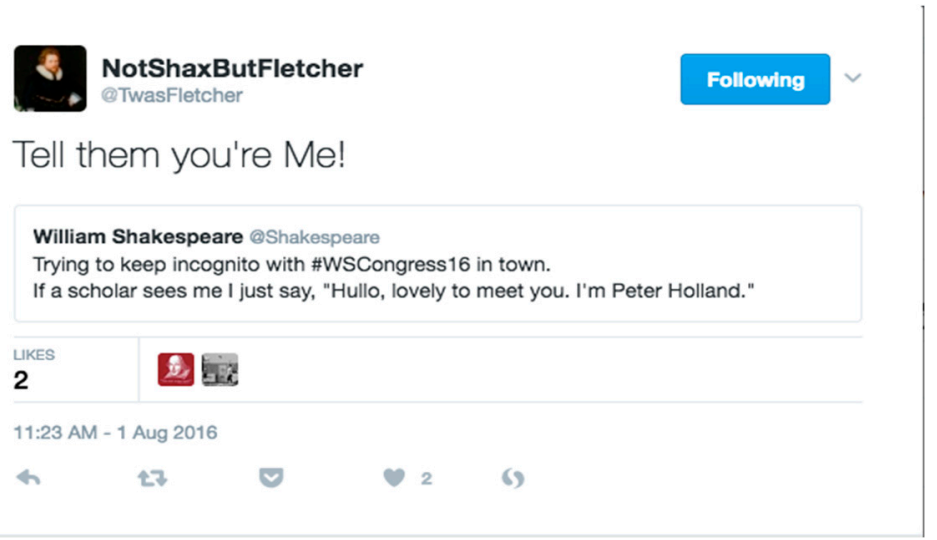

Figure 1. A Twitter interaction between @Shakespeare and @TwasFletcher, 1 August 2016.

The hashtag, \#WSCongress16, refers to the most recent World Shakespeare Congress, hosted between London and Stratford in August 2016. ${ }^{4}$ On the face of it, this Twitter exchange is simply a metatheatrical, performative joke: a lesser-known but still important and recognisable early modern playwright comments on Shakespeare's joke about being recognized (or not) in his home town; the meta-level is that Peter Holland looks a bit like Shakespeare and was the director of the Shakespeare Institute in Stratford, and, of course, that both William Shakespeare and John Fletcher are dead and obviously not using Twitter. The fiction that makes @Shakespeare so much fun is temporarily deployed by Pasupathi, as @TwasFletcher, to generate the kind of in-joke that will be appreciated by the crowd following this hashtag.

On another level, however, there are some complex articulations of authority, estrangement, and marginality at play. For example, the anonymity of @Shakespeare allows Pasupathi, through $@$ TwasFletcher, to co-opt the authority commanded by Peter Holland: the tweet seems simultaneously to say, "[Shakespeare,] Tell them you're Me [Fletcher]!" and, "[Holland,] tell them you're Me [Pasupathi]!" By inserting Fletcher into Shakespeare, Pasupathi herself performs, simultaneously, authority in opposition to Shakespeare and a dominant idea of who a Shakespeare scholar should be or what s/he should do. This is less a comment on Holland himself, and more an acknowledgement of what he represents: the established, implicitly authoritative, and even idealised version of a Shakespearean scholar.

This momentary disruption of Shakespeare's authority via @TwasFletcher is possible precisely because of @Shakespeare's well-maintained anonymity: as I explore in more detail below, the absent faces of the 'ghost tweeters' allow the account to cultivate something akin to William Shakespeare's cultural authority, which rests upon the assumption that he is (and therefore the account represents) a white, cis-het, Christian man. However, untangling the webs of cultural authority at work here is not as easy as saying that @Shakespeare is simply or only a conduit for a white, male authority. In addition, equating Fletcher and Pasupathi is reductive, and in itself a kind of erasure. Although he is not as famous as Shakespeare today, Fletcher was a prominent, Cambridge-educated, white, male playwright. He was hardly the sort of person we could accurately describe as "marginalised". Directionality is important: Pasupathi, here, is claiming Fletcher's authority for herself, and not the other way around, while simultaneously playing on Flethcer's relative marginality in relation to Shakespeare today. The result is partly, and perhaps unintentionally, a comment on her own place in the academy as a woman of colour. The \#WSCongress16 interaction is therefore a microcosm, highlighting the kinds

4 Unlike many major conferences (including Shakespeare Association of America (SAA)), the 2016 World Shakespeare Congress did not advertise a specific social media policy. SAA first published a detailed social media policy for conference delegates in 2015, but this was substantially updated in 2017. See http://www.shakespeareassociation.org/about/saapolicies/social-media-guidelines/. 
of authorities that are at play in a number of online encounters, as well as offline hierarchies that are rehashed, and often amplified, online. @TwasFletcher becomes, in this context, an example of the subversive possibilities afforded by a medium like Twitter.

\section{Theorising Authority, Identity, and Anonymity Online}

Authority, in this case, is a matter of identity. Shakespeare's ghostly self, mediated by @Shakespeare, accrues authority toward himself and defines authority in relation to himself. This is not a phenomenon unique to his digitality, but it is facilitated by the reproductive capabilities of digital culture. In @Shakespeare's case, I suggest that it is also driven by the strict anonymity of the 'ghost tweeters'. In the first chapter of her book Cybering Democracy, Diana Saco looks in detail at the Visible Human Project: an endeavour by scientists, in the last years of the twentieth century, to document and digitise cryosections-frozen slices less than one millimetre thick—of "normal" human bodies, male and female. Saco describes the male 'specimen' - the body of convicted murderer Joseph Paul Jernigan —as 'the otherwise healthy corpse of a well-developed, thirty-nine-year-old male who was free from the ravages of disease, age, and trauma' (Saco 2002, p. xi). Jernigan's digitised body-together with the similarly treated, though anonymous, female specimen-becomes a gateway for Saco's insightful work on cyberspace, democracy, and the ethics of the digital. She argues that 'cyberspace', in many ways, 'redefines the body as abject, as meat' (Saco 2002, p. xxiii) and asks 'What state can the physical body retain in a place like cyberspace?' (Saco 2002, p. xxii). ${ }^{5}$ Noting that the scientists who sectioned Jernigan's corpse were, somewhat ironically, hoping to 'help future researchers dispense with the body' (Saco 2002, p. xxiii, my emphasis), she concludes that 'the cultures that construct cyberspace as a space of bodiless exultation construct the physical body-the body that eats, drinks, sleeps, gets sick, and dies, as Sandy Stone says (Leeson 1996, 114) —as in many respects the abject body, the forgotten body' (Saco 2002, p. xxiv). This meaty abjection becomes a sticky issue for Saco, who wrestles with the paradox that Michel Foucault introduces in Discipline and Punish: in her words, 'if invisibility is disempowering, visibility is a trap $(1979,2002)$. Being seen always comes at a price' (Saco 2002, p. xxv).

Writing several years before the social media revolution, Saco could not, perhaps, have foreseen how Facebook, Twitter, and Instagram, selfies, hashtags, and algorithms might refresh the conundrum she posed in 2002. While it is still true that visibility comes at a price online, the kind of separation from the material body and its conditions that affected Jernigan as he became a sectioned, digitised, and even idealised "male specimen" is now all-but-impossible online for any but 'specimens' such as Jernigan: white, male, conventionally attractive, assumed to be Christian, able-bodied, cis and straight. As Patrick Lonergan notes, 'The arrival of social media has not just created new challenges, but has also exposed the continued existence of problems relating to agency, commodification and visibility in the presentation of female characters in performance spaces', and this goes double for people (and particularly women) of colour, religious minorities, LGBTQI+ individuals, and other marginalised groups (Lonergan 2016, p. 47). Digital spaces are not neutral new frontiers: they are built environments, made by people with biases and preferences that are reflected in their creations:

[i]n other words, given that the majority of computer scientists in the early years of the public Internet were (and are today) male, bodies in cyberspace will be described, represented, and recognized - and, one can extrapolate, addressed - according to the "preexisting codes for body" ([Stone] 14), that is, for gendered bodies, that proliferate in real-world spaces. (De Kosnik 2016, p. 210)

5 The language of the fleshly, 'real' body as 'meat' originates with William Gibson's Neuromancer (1984), often considered the first and certainly one of the most influential cyberpunk novels of the 1980s and 90s. In the novel, the offline world is referred to (derisively) as the 'meatspace', in contrast to 'cyberspace'. 
In other words, marginalised bodies online are not allowed to forget their colour, gender, orientation, religion, ability, or class in the way that "normalised" bodies like Jernigan's might. To appear to be anything other than an idealised male body online is to be scrutinised, marginalised, cryosectioned, examined under a social microscope. While we might argue that movements such as \#MeToo are beginning to change this landscape, statistical data continues to show that women are 'more than twice as likely to experience severe forms of abuse such as stalking or sexual harassment' online (Veletsianos et al. 2018, p. 4691). This is, of course, an intersectional issue, with women of colour and trans women (for example) experiencing significantly higher rates of abuse. Veletsianos et al. also note that 'women who are in the public eye or who use technology to promote their work-such as scholars-are placed at even greater risk' of serious abuse in online spaces. (Veletsianos et al. 2018, p. 4691; see also Duggan 2014).

Empowered forms of invisibility therefore depend upon status and subjectivity: disappearing into a kind of enforced silence can hardly be seen as liberation. Foucault's prison guards, looking down from their Panopticon, are empowered by invisibility and anonymity, while the inmate being observed is vulnerable through visibility. The prisoner is knowable in a way that the guard is not. Furthermore, the invisibility of all the prisoners (or patients, or schoolchildren, or workers) to each other is not an empowered invisibility, but a position of extreme vulnerability, as Foucault explains:

He [sic] is seen, but he does not see; he is the object of information, never a subject in communication. The arrangement of his room, opposite the central tower, imposes on him an axial visibility; but the divisions of the ring, those separated cells, imply a lateral invisibility. And this invisibility is a guarantee of order. [ . . . ] Hence the major effect of the Panopticon: to induce in the inmate a state of conscious and permanent visibility that assures the automatic functioning of power. (Foucault 1995, pp. 200-1)

By putting the inmate in a state of constant visibility and making them aware that they are always potentially watched, the power of the invisible guardians is consolidated and assured. In this sense invisibility does confer power, but perhaps only to those who already hold it.

Twitter-like Shakespeare, and like academia-has long been marked as a space that "doesn't belong" to certain types of people. The ability to disappear in such a space, to be considered neutral or objective (but, crucially, always still a subject: never objectified, never abjected) is a trait associated with white male privilege. As geographer Gillian Rose puts it, "[w]hile men claimed objectivity by denying their specificity and pretending to enact pure reason, women were understood to be incapable of transcending their position" (Rose 1993, p. 9). ${ }^{6}$ The ability of the individual man to stand for the supposedly superior intellect of men and mankind depends upon the assumption that an individual woman (let alone a queer/non-binary person) must be both so outrageously individual as to corrupt their objectivity and so completely subsumed by their gender as to be automatically, inexorably defined by it. Little wonder, then, that the idealised versions of the digital presented in science fiction-and specifically in the cyberpunk fiction of the 1980s_are specifically white masculine fantasies: as Sherryl Vint argues, the 'appeal of cyberspace is linked directly to the representation of the material body in cyberpunk fiction. [... ] The world of cyberspace is the consummate world of the Cartesian dualist: in cyberspace, one is the mind, effortlessly moving beyond the limitations of the human body' (Vint 2007, pp. 103-14). In cyberspace, the male body (with its clear borders and assumed objectivity and neutrality) is constructed as capable of a Cartesian separation in a way that the female (open, leaking, grotesque, borderless, emotional, hormonal) body is not.

And, of course, all of this applies—sometimes with even more force-to scholars of colour: as Arthur L. Little, Jr. reminded us in his Shakespeare Association of America Color of Membership plenary in 2017, objectivity is often a luxury afforded only to white scholars, whose issues are assumed to be universal-in the same way, perhaps, that Shakespeare's plays are seen to address universal

6 We might extend 'women' here to include other marginalised identities. 
themes. The problem of this universality can be seen in an incident that took place at the same conference, as tweeted by another attendee: 'Plenary speaker Prof. Jyotsna Singh lost her name tag \& someone helpfully returned it— to a different Indian scholar \#shakerace \#shakeass17' (8 April 2017). As Sonjay Sharma puts it in 'Black Twitter? Racial Hashtags, Networks, and Contagion', digital identities are 'far from race-neutral', and 'extant racial segregations and inequalities have spilled over into the virtual realm' (Sharma 2013, p. 46). While politicians (notoriously former United States Vice President Al Gore) painted the Internet as a democratic panacea-an evolution of Marshall McLuhan's idealised "global village" - the reality of this 'universalizing discourse' was a tendency toward color-blindness which, as Lisa Nakamura argues, 'permits resources to be unevenly allocated based on racial identities' (Nakamura 2008, pp. 2-3). The 'resources', in this case, represent access to and integration in the digital spaces that have, since 2007-2008, become an inescapable part of everyday life in the West. As Sharma, Nakamura, and others have argued, the 'global village' of the internet is not a neutral clean slate, but rather inheres the prejudices of those who built it. ${ }^{7}$

These same politics are at work even when the creator of content online is unknown: on Twitter, anonymity, remaining or seeming to be invisible can also confer power. If the default assumption is of an archetypal white man, anonymity confers the power of moving through digital territory precisely at the expense of the individualised body. This is not the exultation of leaving the 'meatspace' behind, but rather a hyper-awareness of the limitations placed upon the marked body by a fundamentally racist and hetero-patriarchal society. On social media, the maintenance of anonymity is not just a function of existing structures of power; anonymity generates power, accrues authority around itself, and therefore reinscribes the assumptions that attach to that authority. As Nakamura argues, 'media interactivity is power', and the ability to interact with digital media safely is a function of privilege (Nakamura 2008, p. 176). Retaining anonymity in the face of Big Data-and therefore holding on to some pretence of objectivity, of distance from one's eating, sleeping, affected body-therefore becomes a kind of coup. There are now a number of famous and infamous examples, from author Elena Ferrante to frustrated teenage football fan Sam Gardiner. ${ }^{8}$

\section{Fannish Authority on Twitter}

In examining Shakespeare's relationship to @Shakespeare—and, indeed, Fletcher's relationship to @TwasFletcher-I find the work of fan and fan fiction studies instructive. Fazel and Geddes address the relationship between Shakespearean fan fiction and what they term 'collaborative authority', suggesting that '[a]t the core of Shakespeare fanfic are two intertwined components-the unstable Shakespearean urtext and the ubiquitous presence of the fan author-that seem to exist in a state of perpetual negotiation over the authorized and author-ized text' (Fazel and Geddes 2015, p. 2, emphasis original). This relationship between the official and unofficial meaning-makers in relation to canonical works (Shakespeare as much as Star Trek) is, importantly, coded along race and gender lines, and operates in ways similar to the cyberpunk fantasies examined above.

The playfulness and irreverence of both @Shakespeare and @TwasFletcher are characteristic of fan creations: they remake, reinvent, remediate, and reshuffle the source material (in this case, the historical figures of Shakespeare and Fletcher). As Fazel and Geddes argue, fan fiction shifts 'the point of origin', which results in 'an entire collapse of temporal hegemony, creating an infinitely palimpsested, archontic archive' (Fazel and Geddes 2015, p. 4). This archive, in turn, encourages further fan creation: we might think of @TwasFletcher, in this sense, as a kind of remediation of @Shakespeare as much as of Shakespeare-a relationship to which I will return later in this article. The 'collapse of temporal hegemony' that Fazel and Geddes identify also creates the very possibility

7 See also Nakamura on 'Measuring Race on the Internet: Users, Identity, and Cultural Difference in the United States' in Digitizing Race: Visual Cultures of the Internet, pp. 171-201.

8 Lonergan (2016) gives a detailed account of Gardiner's use of false identities on Twitter in Theatre E Social Media, pp. 1-3. 
of a ghostly, undead Shakespeare on Twitter: the fannish impulse to extend a character's storyline or put certain characters into a 'Modern AU' or 'alternate universe' is active in @Shakespeare. This ghostly presence of a fannish Shakespeare character in the present 'playfully interrogates the genres that it exploits, and in doing so, exists as a type of screenshot of Shakespeare's place in the popular imagination' (Fazel and Geddes 2015, p. 4). As I will examine in more detail below, @Shakespeare is not Shakespeare: for one thing, he is more politically progressive and always willing to make his views explicit.

In theorising @Shakespeare and @TwasFletcher as fan creations, however, it would be impossible to ignore the ways in which Shakespeare's cultural capital inflects his fandom. In Textual Poachers, Henry Jenkins pushes on what he terms 'mythologies' of 'fannish identity': that fans are wasting their time engaging in depth with pop culture canons such as Star Trek, Star Wars, or Harry Potter (Jenkins 2013, p. 11). Unlike these examples, it is not typically considered a waste of time or uncouth to have detailed, even encyclopaedic knowledge of Shakespeare's life and works. Whereas, say, 'Trekkies' are often depicted as asexual or sexlessly feminised (Jenkins 2013, p. 15), Shakespeare enthusiasts are historically associated with the archetypal white male professor, a beacon of scientific reason, economic success and cultural capital (Jenkins 2013, pp. 10-12). The Shakespearean canon is therefore both like and unlike the Star Trek canon: although its origins are in popular "low" culture, it has, over the centuries, cemented itself as the epitome of high culture: a marker not just of taste but of education, class, and skill that makes its fans (and its relationship to fandom) a slightly different breed. As Jenkins notes, 'Fan culture muddies [the] boundaries, treating popular texts as if they merited the same degree of attention and appreciation as canonical texts'; but, conversely, fan culture treats canonical texts such as Shakespeare's as equally ripe for transformation and remediation (Jenkins 2013, p. 17). While Shakespeare fans are no less 'active producers and manipulators of meaning', Shakespeare's ivory-tower affiliation changes the relationship between those who appropriate and re-read his works and those who study and perform them professionally: there is both more overlap and more conflict (Jenkins 2013, p. 23).

John Fletcher's, on the other hand, is an obscure fandom, populated by the fringes of academic or theatrical praxis; a niche interest that has yet to attract even the kind of attention that, say, Coriolanus has since Tom Hiddleston played the title role (cf. also Hiddleston's shower gif from The Hollow Crown on the BBC). ${ }^{9}$ While Star Trek has yet to be accepted as a pillar of Anglophone cultural heritage, Shakespeare is entrenched as such, and therefore a fanatic obsession (Jenkins 2013, pp. 10-12) with his works is considered socially acceptable, if not downright healthy, like a kind of intellectual kale. Shakespeare's cultural authority (and, somewhat ironically, his suitability for fannish adaptation) is implicit.

\section{5. @Shakespeare: Performing Implicit Authority}

Here, we return to @Shakespeare. @Shakespeare's popularity comes partly because it is 'findable' and 'discoverable', easy to stumble upon in the ever-increasing noise of a Twitter feed; easy to remember so that it can be re-discovered, intentionally, at a later date. ${ }^{10}$ Authority is therefore established and performed by @Shakespeare in a number of ways, as one of the account's managers confirmed when I interviewed them via Twitter's Direct Message feature, which allows for "private" one-to-one or small group messaging within the platform itself. This method of communication allowed for the maintenance of @Shakespeare's anonymity: rather than moving off-site to an email address or other messaging app (many of which are tied to mobile phone numbers), using Twitter Direct Messages or "DMs" put me directly in contact with @Shakespeare, as @Shakespeare.

9 See Blackwell (2018), Shakespearean Celebrity in the Digital Age: Fan Cultures and Remediation. London: Palgrave, especially Chapter 3: 'Performing the Shakespearean Body: Tom Hiddleston Onstage and Online'.

10 'Findability' is an industry term used to describe the discoverability or availability of a given piece of digital culture. See, e.g., Kerric Harvey (ed.), Encyclopedia of Social Media and Politics. London: Sage, (Harvey 2014). 
When I asked @Shakespeare if there was a particular strategy driving their relative popularity on Twitter, they drew attention to what they call the 'real estate' of the handle itself:

Well I think part of it is simply the Twitter handle. The @shakespeare address is a small, strategic bit of online real estate, and it means that some people unwittingly evoke us just by adding the@. (@Shakespeare 2017)

This 'bit of online real estate' makes the account more accessible than similar efforts such as @Wwm_Shakespeare. And yet, for all its visibility—discoverability, findability-the account is stringent in its maintenance of anonymity. In my interviewee's words,

... it's part of the @Shakespeare DNA to keep the ghost-tweeter(s) anonymous. It has just always seemed funnier and more effective to commit to the fiction that this is really William Shakespeare. [ ... ] So one of the basic rules is that no one can find the tweeter(s) [sic] identities online. This is not a secret to everyone, but it is a secret to the Internet. (30 May 2017)

The 'ghost-tweeter(s)' capitalise upon that secret, and my interviewee suggests that the account has been popular-and relatively immune to 'trolling' and abuse—partly because it 'assumes Shakespeare's authority instead of grasping for it' (@Shakespeare 2017, my emphasis). This is a powerful assumption in that it encompasses not merely the continuing cultural cache of Shakespeare's canon, but the capital wielded by the entire 'surfeit of Shakespeares' (O'Neill 2018, p. 121), the coincidence of historical and cultural factors that define what 'Shakespeare' means in the present. As Fazel and Geddes remind us,

what is collectively represented or defined as Shakespeare is continuously being reminagined and reconstructed in accordance with the affordances of the medium in which he appears and the purposes to which he is put to task. (Fazel and Geddes 2017, p. 2)

Scholars and particularly artists have long embraced the 'possibility that history, even long dead history, does not have to remain static' (Rosvally 2017, p. 162); the digital, however, makes these processes clearer, more transparent, and more accessible to intervention from a variety of actors. @Shakespeare, then, is one such actor, who intervenes in the continuous re-making of Shakespeare to stake its claim to the authority contained therein.

While the exact identities of the account's managers are unknown, the account's feed suggests high-level—even expert—knowledge not only of Shakespeare's canon, but of early modern theatrical and literary culture more broadly. While some of @Shakespeare's tweets 'can be enjoyed by users who lack intimate knowledge of Shakespeare's texts' (Rosvally 2017, p. 159), the target audience appears to be those who share expertise with the 'ghost tweeters'. Consider, for example, a tweet sent from the account during its 2017 haunting of Los Angeles, which also encapsulates its iconic sense of performative meta-humour:

Donne hath rented us a Tesla Model S. It turns itself on as Marlowe gets behind the wheel.

Jonson looks for a ghost.

There are 4.

\#ShakesLA (24 February 2017)

Aside from the geeky satisfaction of a joke (or, in this case, a whole series of jokes) about John Donne, Christopher Marlowe, Ben Jonson, and William Shakespeare hanging out in Los Angeles together, this tweet trades on the reader's knowledge of Elon Musk's electric car and its functionality as much as niche early modern authors. This is Shakespeare's—and @Shakespeare's_-'uncanny temporality' in action: a joke groaning under the weight of 400 years (O'Neill 2018, p. 122). But whereas knowledge of how a Tesla Model S functions might be considered popular (if not yet common) knowledge in 2017, it is perhaps less likely that the average Twitter user would recognise and understand enough about Donne, Marlowe, and/or Jonson to be in on the joke. 
Such in-crowd, nerdy joking is a trademark of @Shakespeare's content. This performance of authority often asserts itself playfully, as in interactions with other literary ghost accounts and through citation of the more obscure Shakespearean lines, characters, and plays. Consider, for example, this exchange with the more niche account @_BenJonson_, with whom @Shakespeare frequently interacts:

@Shakespeare: 'On the boardwalk at Venice Beach, asking passers by of [sic] they want to wage on the Three Caskets game.' \#ShakesLA

@_BenJonson_: '(We let @Shakespeare do this. It keeps him from running up to every spray-painted statue performer \& crying "Music! Awake her!") \#ShakesLA' (25 February 2017).

The success of the jokes, here, relies on the reader's knowledge of-at a minimum-The Merchant of Venice and The Winter's Tale, making it a satisfying in-joke for Shakespeare scholars, practitioners, and enthusiasts. The account trades on this level of engagement from those who know Shakespeare's works inside and out, using even his most obscure plays to make topical jokes: 'Don't let Coriolanus defecting to the Volscians and marching on Rome distract you from the big things' (20 May 2017). This is a performance not only of Shakespearean authority - that is, a performance of an 'author-ized' (Fazel and Geddes 2015) Shakespearean self-but also a performance of fannish authority, that manipulates and reconstitutes both the historical figure of Shakespeare and his canon to accommodate new situations, relationships, and narratives.

This link to fan and fan fiction studies is also useful in understanding @Shakespeare's politics. Shakespearean authority—variously cultivated-manifests in another, particularly relevant way in @Shakespeare's feed: although the account is quick to provide hot takes on current events and debates, joke about global and academic politics, and espouse 'woke', socially progressive principles, it encounters little (if any) backlash. My ghost-tweeter interviewee confirms this impression: 'The character speaks from the height of cultural authority, which licenses him to be as informal or grumbly or self-deprecating as he pleases' (2017). As the tweet quoted above also demonstrates, twenty-first-century left-wing political cred is a crucial component of @Shakespeare's authority. Consider, for example, tweets like this one, which parodies similar tweets published by Donald Trump: 'Losers Malcolm and Donalbain started this witch hunt as an excuse for their father's murder. Their fault! I have never met any witches! SAD!' (12 May 2017). Or this one, playing on Trump's accusation that former president Barack Obama had ordered the CIA to tap his phones: 'Is British Intelligence taping [sic] thy phones? It depends./Be thy name, "Mary, Queen of Scots"?' (16 March 2017). Clearly, @Shakespeare is not afraid to get political—and this "clicktivism" comes at remarkably little cost to the account's managers, at least in terms of public backlash. The relative safety that @Shakespeare experiences is at least partly attributable to its affiliation with William Shakespeare: he is, in many ways, the epitome of white, male, Christian authority, and his centrality to literature, drama, and cultural heritage comes at the expense of other writers-not just other Renaissance playwrights, and not just in English. This relationship to patriarchal and imperialist authority clearly links to the social forces that make women and other marginalised populations particular targets for harassment online. That @Shakespeare is relatively safe from trolling cannot be separated from the knowledge that William Shakespeare was the kind of man whom we would expect to be safe from trolling.

This relationship goes both ways: although @Shakespeare largely falls on the left-wing/ progressive side of the political spectrum (at least as defined in the Anglophone West), Shakespeareans-academics, theatre practitioners, and enthusiasts alike-are not uniformly progressive. Among our numbers are racists, misogynists, imperialists, homophobes, and garden-variety assholes; such people are certainly not unique to Shakespeare Studies or even to academia, but we are far from immune to their influence. As a field, we tout Shakespeare's supposed "universality" and "timelessness" as if these things are unproblematically positive: but is it really a good thing that Othello and Measure for Measure continue to feel relevant to twenty-first-century readers and audiences? 
While @Shakespeare is obviously not responsible for the actions of Shakespeare's fans online, I would be remiss to ignore the ways in which a professed love of Shakespeare intersects with trolling and other abusive behaviours on Twitter. That Shakespeareans participate as much as any other group in targeted online harassment is evident in a number of recent examples. In considering the problem of Shakespeare's troll army, David C. Moberly's cautionary questions come to mind: 'Whose image of Shakespeare is being policed, protected, and celebrated' in the supposedly democratic, participatory spaces of social media? (Moberly 2018, p. 98). While I could certainly pick up the backlash against Emma Rice when she was hired—and, later, when she stepped down —as Artistic Director of Shakespeare's Globe, I want to focus on an example from a less public figure. ${ }^{11}$

Dana Dusbiber is a California schoolteacher who had the audacity to suggest, in 2015, that her diverse student body might be better served by a curriculum that includes literature from Asia and Africa, rather than an entirely Eurocentric reading list based around Shakespeare. When her letter to the Washington Post was published by Valerie Strauss (Strauss 2015), the trolls attacked. Brent from Texas tweeted: 'Dana Dusbiber is why I support cutting public school funding. She proves we're not getting a good value. \#racism \#fail' (15 June 2015). Michael from California felt the need to tweet: 'Dana Dusbiber, you aren't very smart' (17 June 2015). Ivan from Washington, DC, proclaimed that 'Dana Dusbiber appears not qualified to clean baby poop. What is she doing teaching high school?' (19 June 2015). Janet went after Dusbiber's job, tweeting the school's phone number and telling her followers to 'COMPLAIN!' because an 'Ignoramus teacher doesn't want to teach Shakespeare' (16 June 2015). Violet, whose display name includes 'MAGA', also tweeted out the school's phone number, telling followers to 'Call this idiot \& call the school PRINCIPAL too' (15 June 2015). The attacks went on and on: as you can see from the publication dates of these tweets, the backlash was still coming six days after Dusbiber's letter was published on 13 June. The furore built so swiftly that the Post published a combative response piece by Matthew Truesdale the very same day, although (to their credit) neither Strauss nor Dusbiber retracted the original article.

Dusbiber offers one particularly potent example of Shakespeare's authority deployed in the interests of distinctly conservative (as opposed to progressive) politics. Her experience sets the stage for my analysis of @TwasFletcher by demonstrating the sometimes aggressive reactions to those who challenge the entrenched authority of Shakespeare.

\section{6. @TwasFletcher: Transforming Shakespeare's Authority}

@TwasFletcher is a bot, an automated account that can perform many of the same functions a human user might: for example, a bot can write and publish tweets, retweet or reply, send direct messages, and follow or unfollow other accounts. Until very recently, bots on Twitter were largely unregulated, and just about anyone with the ability to write (or copy) the code could build one. ${ }^{12}$ $@$ TwasFletcher was designed to do a few different things. According to Paspupathi, it retweeted tweets about Shakespeare, but with a few key changes: @TwasFletcher 'replace[d] all references to Shakespeare with Fletcher, change[d] William to John, and even replace[d] Billy Shakes with "J Fletch"'. Pasupathi goes on to say that the bot 'also replace[d] some popular play titles with ones that will be less

11 Shakespeare's Globe announced the appointment of Emma Rice as their third Artistic Director on 1 May 2015. This was a controversial choice from the start, with Rice confessing to the press that she had previously directed only one Shakespeare play (Cymbeline) and that reading Shakespeare's plays often 'left her "very sleepy"' (Furness 2016). In October 2016, barely six months after Rice had taken up her post, the Globe announced that she would be stepping down after her second season. The announcement, exacerbated by the reasoning given in the Globe's press release (a desire to return to 'shared light' productions 'without designed sound and light rigging' (Brown 2016)), triggered enormous and immediate backlash on Facebook and Twitter, with \#EmmaRice trending as both supporters and detractors weighed in. Rice later published a pull-no-punches letter to her successor, which addressed some of the controversy and was published to the Globe's blog (Rice 2018).

12 Following the Cambridge Analytica data mining scandal, and investigations into foreign governments' potential interference in the 2016 Presidential election in the United States and the EU referendum in the United Kingdom, Twitter updated their 'Automation Rules' in January 2018 (Roth 2018). 
familiar to many Shakespeare fans outside of academia, and, on occasion, [ . . ] replace[d] character names in Shakespeare's works with the names of characters in Fletcher'. Consider, for example, this tweet from @TwasFletcher, which appropriated a tweet from Beverly about Michael Fassbender starring as Macbeth: 'Anyone else getting over-excited by the prospect of Fassbender's \#Valentinian? \#fullofscorpionsismymind' (20 September 2015). The bot's success and humour resides in its ability to create friction between Fletcher's relative obscurity and Shakespeare's (usually unquestioned) ubiquity. In doing so, @TwasFletcher creates a kind of absurd microcosm, a parody world where John Fletcher is the poet 'not for an age, but for all time'. We laugh at @TwasFletcher's content because it throws the extent of Shakespeare's cultural authority into relief, as demonstrated by these rewritten tweets:

'The \#FletcherSunday tag is amazing because after 5 centuries, his works are still treasured and performed' (20 September 2015).

'Okay he just referred to Fletcher as "J. Fletch" and thats [sic] where I draw the line' (30 September 2015).

‘There are so many awesome \#FletcherSunday quotes!' (27 September 2015).

These examples are particularly relevant in their co-option of \#ShakespeareSunday, a weekly meme tradition created by fans of the BBC Shakespeare histories series The Hollow Crown (@HollowCrownFans). \#ShakespeareSunday encourages followers to tweet their favourite Shakespeare quotations, every Sunday, 'often unified around specified themes or commemorative events' that 'enable users to demonstrate their knowledge of Shakespeare' (Mullin 2018, pp. 214-15). ${ }^{13}$ $@$ TwasFletcher's intervention here is therefore doubly significant for its interruption and interpolation of a longstanding (in Twitter terms) and enormously popular Shakespeare meme.

Although the bot is no longer active, its archive of rewritten tweets is especially noteworthy here for its lack of anonymity: Pasupathi was public and open about her creation of @TwasFletcher, and she detailed her methodology and the techniques she used to automate the account in an introduction posted to her professional website. ${ }^{14}$ In her introduction, Pasupathi makes clear her motivations for undertaking this social media experiment:

What does it look like when we replace Shakespeare with Fletcher, if only in digital spaces? How do people respond when they find a name they don't expect? Do Fletcher's lines [ ... ] sound worthy of being passed around? (Pasupathi 2015)

Unlike @Shakespeare, there is no cloak of anonymity around @TwasFletcher. Pasupathi does borrow Fletcher's likeness under the auspices of @TwasFletcher, but only intermittently—and even when she does so, there is always a clear path back to her, the material fact of her brown, female body and her status as a professor in a notoriously old, white, and male field. For those in the know, it becomes a kind of joke: we interact with @TwasFletcher knowing that, on some level, we are interacting with Pasupathi. There is no such awareness embedded in @Shakespeare: most who interact with the account do not know who its authors are, and there is no trail back to them through the account bio or other public-facing record. It is not possible to have the same level of awareness, the same sense of interacting with a person that @TwasFletcher provides, despite the fact that @TwasFletcher is primarily automated (a bot) and @Shakespeare's content is user-generated.

Given these distinctions, the facts of Pasupathi's particular body are relevant: as a woman of colour in an academy and, more particularly, a subject area that has historically been the preserve of white men, it matters that @TwasFletcher leads back to her when the account receives vitriolic responses from Shakespeare's fans online. @TwasFletcher's authority—unlike @Shakespeare's—is

13 For a more thorough account of the relationship between @HollowCrownFans and \#ShakespeareSunday, see (Mullin 2018).

14 See https://vcpasupathi.wordpress.com/current-research/replaceshaxwithfletch/. 
always filtered through Pasupathi's own. Pasupathi herself foregrounds this link between herself and the bot, consistently directing disgruntled or delighted respondents back to the webpage that explains the experiment. Those in the know-mostly other scholars-sometimes even tag Pasupathi's personal Twitter account in their responses to the bot. While most of the responses to @TwasFletcher are either positive or confused, a few interactions are noteworthy for their outsized aggression toward the bot's interruption of Shakespeare's cultural authority. Arrows \& Traps, a London theatre company that self-describes on its Twitter profile as 'specialising in classic adaptation and historical female-led new writing', reacted very negatively to @TwasFletcher's rewrites, even going so far as to report the bot to Twitter (Figure 2):

'@TwasFletcher You should know that we've reported you to Twitter and asked for these to be removed. Finally, a reason for the block button.'

They also likened Pasupathi to a 'golem' 'burning our village' (Figure 3):

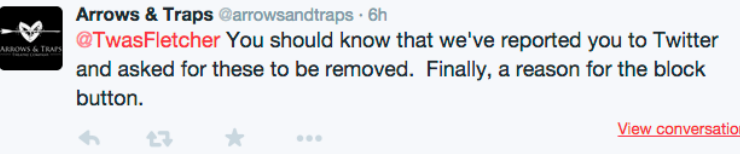

Figure 2. Tweet to @TwasFletcher from @arrowsandtraps.

Arrows \& Traps

@DalekGirl93 Thanks for the heads-up it's so annoying! Hopefully now we've found the puppet-master, the golem will stop burning our village

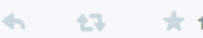

Figure 3. Tweet to @DalekGir193 regarding @TwasFletcher from @arrowsandtraps.

Eventually, Arrows \& Traps tweeted at Pasupathi directly, on her personal Twitter account, to ask her to make the bot 'cease and desist'. When Pasupathi responded to ask how the tweets had offended them, Arrows \& Traps replied with a telling comment on Shakespeare's cultural capital in relation to Fletcher's: ' . . it was taking tweets about our show and changing shrew into tamer tamed. I wouldn't have minded but Fletcher was talentless' (29 May 2015).

As Pasupathi put it herself in a presentation for the 2017 MLA conference, tweets like these 'say more about these users' personal investments in Shakespeare and the status of Shakespeare as a construct and marker of social capital than they do about Fletcher's talent' (Pasupathi 2017). They also, however, reactivate Jenkins' discussion of the role of taste in the cultural boundary-setting that disparages fannishness:

The boundaries of "good taste," then, must constantly be policed; proper tastes must be separated from improper tastes; those who possess the wrong tastes must be distinguished from those whose tastes conform more closely to our own expectations. Because one's taste is so interwoven with all other aspects of social and cultural experience, aesthetic distaste brings with it the full force of moral excommunication and social rejection. "Bad taste" is not simply undesirable; it is unacceptable. (Jenkins 2013, p. 16)

In challenging Shakespeare's authority via a lesser-known early modern playwright, Pasupathi also challenges the boundaries of good taste. This perceived assault on the boundaries of Shakespeare's cultural authority is significant for its connection to Pasupathi as much as its affiliation with Fletcher: she represents (and, through her bot, enacts) a challenge to the status quo of Shakespeare Studies and pop culture Shakespeare alike.

The clear route from @TwasFletcher back to Pasupathi-which she often facilitated through clarifying responses to confused tweeters-allows some of the negative responses to @TwasFletcher 
to attack her personally. In addition to the Arrows \& Traps tweet cited above, Shakespeare Magazine's account claimed that Pasupathi was classless and attention-hungry, and tagged her personal account when making this accusation: 'While we're on the subject of staying classy, @[Pasupathi], maybe you could stop trolling Shakespeare to get attention for your research?' (19 June 2015). Far from an innocuous spat, this kind of attack characterises the attempts to 'silence and marginalise women scholars' voices' that have become commonplace for public-facing women-and particularly women of colour-who share their academic work online (Veletsianos et al. 2018, p. 4690). That Pasupathi is such a woman who is also interrupting the well-established authority wielded by Shakespeare compounds the problem: not only is she promoting her own work by linking respondents back to her professional website, she is also using that work to chip away at a fiercely protected national treasure.

Given that Pasupathi intervenes in Shakespeare's authority via a non-human, fleshless bot, I want to return to the language of meatspace and cyberspace articulated by Saco (via Gibson) above. In the context of cyberpunk discourse, it is relevant that @Shakespeare's anonymity allows the assumption of a patriarchal authority, whereas Pasupathi's transparent relationship to the cyborg @TwasFletcher makes her, personally-her offline self-a target for abuse. This connects to the masculine cyborg fantasies that I discuss above; De Kosnik articulates this problem succinctly in Rogue Archives:

Many works of cyborg discourse envision a near-future of human-machine (ranging from complete merging to entrenched warfare between the two parties) in which "human" is equated with femaleness. [ ... ] This is a persistent trope in visions of the future that circulated during the 1980s and 1990s: as the flesh appears ever weaker and decreasingly mandatory in the face of technology's galloping developments, women become the "natural preserve" of human embodiment, the memory-keepers of, and advocates for, the importance and significance of physicality. (De Kosnik 2016, pp. 203-4).

Of course, @Shakespeare's anonymity is nothing intentionally sinister or underhanded: the ghost-tweeters assert that it is simply 'more fun' to pretend that Shakespeare himself is on Twitter. In this case, it means hiding in plain sight. The managers of @Shakespeare exist: they are flesh-and-blood humans who nonetheless are invisible to most who interact with the account. The lack, in this case, of a tangible, embodied person to whom we can attach the activities of @Shakespeare allows Shakespeare (the man, the myth, the legend) to haunt @Shakespeare more thoroughly-and, in doing so, entrench the image of Shakespeare as man. As Rosvally puts it, @Shakespeare 'generates creative fictions about the figure of Shakespeare that ask users to envision the ghost's presence in their daily lives' (Rosvally 2017, p. 156). @TwasFletcher does something similar, but with an additional layer of haunting: by reconfiguring tweets about Shakespeare as tweets about Fletcher, it performs an alternative history that interpolates itself into our horizon of expectation. John Fletcher's haunting of @TwasFletcher is of a totally different kind, both because Fletcher lacks Shakespeare's ubiquity and because Pasupathi interrupts the ghostly presence, layering herself between Fletcher and @TwasFletcher in deliberate and significant ways.

\section{Conclusions: Remediating Ghostly Authority}

It would be easy to dismiss @TwasFletcher as just a bit of academic fun, but I want to suggest that there is a more serious point to be made about disrupting Shakespeare/@Shakespeare and his authority on Twitter, if only temporarily, and publicising a playwright who, arguably, writes more interesting and more diverse women and characters of colour than Shakespeare: see, for example, the female, Indonesian, Muslim protagonist of The Island Princess, or the "shrew" who emphatically does not place her hand below her husband's foot in The Tamer Tam'd. Boosting plays like these into the Twitter public's field of vision creates a kind of Verfremsdungeffekt in relation to the ubiquity of Shakespeare, encouraging the readers of @TwasFletcher's tweets to make Shakespeare strange and to look beyond his works, if only within the wider canon of early modern drama, for protagonists who 
perhaps speak more appropriately to the present moment. This, in and of itself, makes @TwasFletcher a worthwhile experiment.

As I argue throughout this article, it matters very much that there is no face but Shakespeare's attached to @Shakespeare and that, conversely, there is a very specific face attached to @TwasFletcher. If, as Kidnie suggests, 'in everyday and specialist usage people feel able, and some are even determined, to flag not all but specifically some Shakespearean production(s) as "not quite" Shakespeare' (Kidnie 2009, p. 5), it is worth asking whose and which Shakespeares are questioned, and which are left undisturbed (cf. Moberly 2018). As Sujata Iyengar points out, Shakespeare's playtexts 'antedate current US [and UK] copyright law', and therefore 'what we do with him/it is necessarily transformative' (Iyengar 2017, pp. 1, 5). In that case, what makes one iteration more or less authentically (authoritatively) Shakespearean than another? And, crucially, is @TwasFletcher merely another transformation of Shakespeare, or something more disruptive? After all, Iyengar defines 'transformative Shakespeares' as cultural productions that

recreate Shakespearean and literary ontologies (What is Shakespeare? What is literary?), genres and media (Where do we find Shakespeare? What elements do we consider Shakespeare?), motives and audiences (For whom and to whom is this Shakespeare?) and markets (Who is capitalizing from or on Shakespeare, and in what ways?). (Iyengar 2017, p. 1)

Framed in this way, we might think about @TwasFletcher as a kind of carnival version of @Shakespeare-and @Shakespeare, in turn, as a carnival Shakespeare. As De Kosnik and Donald Theall have argued, it is easy to connect internet cultures to the idea of the carnival because Marshall McLuhan's theory of the global village echoes Mikhail Bakhtin:

Carnival does not know the footlights, in the sense that it does not acknowledge any distinction between actors and spectators [ ... ]. Carnival is not a spectacle seen by the people; they live in it, and everyone participates because its very idea embraces all people. (De Kosnik 2016, p. 7)

The other key to carnival is that it is a temporary state, when the laws that normally apply are sub/inverted and topsy-turvy rules. In this sense, we can think of @TwasFletcher as a kind of brief, carnivalesque inversion that 'infuse[s] its participants with a conviction that the prevailing social and cultural order and structure need not always prevail' (De Kosnik 2016, p. 177). Pasupathi's experiment embodies the carnivalesque in its limited time frame and in its gleeful subversion of the Shakespeare-centric narrative of early modern drama and culture. The identity-swapping that takes place in the \#WSCongress16 tweet discussed above offers a potent example: not only does Fletcher (lesser-known, less exalted early modern playwright) co-opt the authority of Shakespeare (shining star, ubiquitous early modern playwright), but-through this topsy-turvied relationship between Fletcher and Shakespeare-Pasupathi turns Shakespearean academic hierarchy on its head as well, tugging on the authority of Peter Holland and broadcasting her own voice in the process.

It is @Shakespeare, however, that embraces the 'no footlights' approach to carnival, where the distinction between reality and fiction recedes (even within the hyper-mediated Twittersphere). For all its topsy-turvy fun, @TwasFletcher is self-consciously constructed, and its performance of Fletcher's identity, as I discuss above, is filtered through Pasupathi's transparent creation and management of the account. This distinction between the two accounts can also be understood through Bolter and Grusin's spectrum of remediation, running from immediacy on the one hand to hypermediacy on the other. Immediacy describes the desire to 'erase all traces of mediation' that defines @Shakespeare's approach: the tendency of media to disappear and to create the illusion of integration into everyday life, into the platforms and hardware that support them (Bolter and Grusin 1999, p. 53). The conspicuous absence of @Shakespeare's managers contributes to the account's sense of immediacy, in Bolter and Grusin's meaning. Conversely, @TwasFletcher is hypermediated, like a clock with its face pulled off so that all the gears are on show. Pasupathi goes to great lengths to show us how @TwasFletcher works, 
to multiply the media involved and, in doing so, to draw attention to the layers of mediation involved in creating and managing the account. When looking at the two accounts side-by-side, however, the effect of the immediacy of @Shakespeare is to cement or entrench the authority that the account so successfully assumes.

Funding: This research received no external funding.

Acknowledgments: The author wishes to acknowledge the contributions of @Shakespeare's anonymous 'ghost-tweeters' and Vimala C. Pasupathi, who were very generous in sharing their work and thinking.

Conflicts of Interest: The author declares no conflict of interest.

\section{References}

@Shakespeare. 2017. Twitter Direct Message to the author. May 30.

Benjamin, Walter. 2002. The Work of Art in the Age of Its Reproducibility. In Walter Benjamin: Selected Writings. Edited by Howard Eiland and Michael W. Jennings. Translated by Edmund Jephcott, Howard Eiland, and et al.. Cambridge: Belknap Press, pp. 101-33, First publish 1936.

Blackwell, Anna. 2018. Shakespearean Celebrity in the Digital Age: Fan Cultures and Remediation. London: Palgrave. Bolter, Jay David, and Richard Grusin. 1999. Remediation: Understanding New Media. Cambridge: MIT Press.

Brown, Mark. 2016. Emma Rice to Step Down as Artistic Director at Shakespeare's Globe. Guardian. October 25. Available online: https://www.theguardian.com/stage/2016/oct/25/emma-rice-step-down-artisticdirector-shakespeares-globe (accessed on 22 February 2019).

Calbi, Maurizio. 2013. "He Speaks ... Or Rather ... He Tweets": The Specter of the "Original", Media, and "Media-Crossed" Love in Such Tweet Sorrow. In Spectral Shakespeares: Media Adaptations in the Twenty-First Century. New York: Palgrave Macmillan, pp. 137-62.

Clarke, Barry R. 2019. Francis Bacon's Contribution to Shakespeare: A New Attribution Method. London: Routledge.

De Kosnik, Abigail. 2016. Rogue Archives: Digital Cultural Memory and Media Fandom. Cambridge: MIT Press.

Duggan, Maeve. 2014. Online Harassment. The Pew Research Centre: Internet, Science and Tech. Available online: http://assets.pewresearch.org/wp-content/uploads/sites/14/2014/10/PI_OnlineHarassment_ 72815.pdf (accessed on 1 February 2019).

Fazel, Valerie M., and Louise Geddes. 2015. 'Give Me Your Hands If We Be Friends': Collaborative Authority in Shakespeare Fan Fiction. Shakespeare 12: 274-86. [CrossRef]

Fazel, Valerie M., and Louise Geddes. 2017. Introduction: The Shakespeare User. In The Shakespeare User: Critical and Creative Appropriations in a Networked Culture. Edited by Valerie M. Fazel and Louise Geddes. London: Palgrave Macmillian, pp. 1-22.

Foucault, Michel. 1995. Discipline and Punish: The Birth of the Prison. New York: Vintage Books.

Furness, Hannah. 2016. Emma Rice: 'A lot of Shakespeare feels like medicine'. Telegraph. January 16. Available online: https:/ / www.telegraph.co.uk/theatre/actors/emma-rice-a-lot-of-shakespeare-feels-like-medicine/ (accessed on 22 February 2019).

Harvey, Kerric. 2014. Encyclopedia of Social Media and Politics. London: Sage.

Iyengar, Sujata. 2017. Shakespeare Transformed: Copyright, Copyleft, and Shakespeare After Shakespeare. Shakespeare après Shakespeare [Shakespeare After Shakespeare]. Paper presented at Société Française Shakespeare Conference, Paris, France, January 20-23. Edited by Anne-Valérie Dulac and Laetitia Sansonetti. Available online: https://journals.openedition.org/shakespeare/3852 (accessed on 1 February 2019).

Jenkins, Henry. 2006. Convergence Culture: Where Old and New Media Collide. New York: NYU Press.

Jenkins, Henry. 2013. Textual Poachers: Television Fans and Participatory Culture. London: Routledge.

Kidnie, Margaret Jane. 2009. Shakespeare and the Problem of Adaptation. Abingdon: Routledge.

Lonergan, Patrick. 2016. Theatre \& Social Media. London: Palgrave.

Moberly, David C. 2018. 'Once More to the Breach!': Shakespeare, Wikipedia's Gender Gap, and the Online, Digital Elite. In Broadcast Your Shakespeare: Continuity and Change Across Media. Edited by Stephen O'Neill. London: Bloomsbury Arden, pp. 87-104.

Mullin, Romano. 2018. Tweeting Television/Broadcasting the Bard: @HollowCrownFans and Digital Shakespeares. In Broadcast Your Shakespeare: Continuity and Change Across Media. Edited by Stephen O'Neill. London: Bloomsbury Arden, pp. 207-26. 
Murthy, Dhiraj. 2013. Twitter: Social Communication in the Twitter Age. Cambridge: Cambridge University Press.

Nakamura, Lisa. 2008. Digitizing Race: Visual Cultures of the Internet. Minneapolis: University of Minnesota Press.

O'Neill, Stephen. 2018. Shakespeare's Digital Flow: Humans, Technologies and the Possibilities of Intercultural Exchange. Shakespeare Studies 46: 120-33.

Pasupathi, Vimala C. 2015. \#NotShaxButFletch. Available online: https:/ /vcpasupathi.wordpress.com/currentresearch/replaceshaxwithfletch/ (accessed on 1 February 2019).

Pasupathi, Vimala C. 2017. Digital Fletcher. Paper presented at the MLA Convention, Philadelphia, PA, USA, January 5-8.

Rice, Emma. 2018. A Letter from Artistic Director Emma Rice. Shakespeare's Globe Blog. April 19. Available online: https:/ /blog.shakespearesglobe.com/tagged/A-Letter-From (accessed on 22 February 2019).

Rose, Gillian. 1993. Feminism and Geography: The Limits of Geographical Knowledge. Minneapolis: University of Minnesota Press.

Rosvally, Danielle. 2017. The Haunted Network: Shakespeare's Digital Ghost. In The Shakespeare User: Critical and Creative Appropriations in a Networked Culture. Edited by Valerie M. Fazel and Louise Geddes. London: Palgrave Macmillian, pp. 149-66.

Roth, Yoel. 2018. Automation and the Use of Multiple Accounts. Twitter Developer Blog. February 21. Available online: https://blog.twitter.com/developer/en_us/topics/tips/2018/automation-and-the-use-of-multipleaccounts.html (accessed on 1 February 2019).

Saco, Diana. 2002. Cybering Democracy: Public Space and the Internet. Minneapolis: University of Minnesota Press.

Sharma, Sanjay. 2013. Black Twitter?: Racial Hashtags, Networks and Contagion. New Formations: A Journal of Culture/Theory/Politics 78: 46-64. [CrossRef]

Smith, Emma. 2017. Shakespeare: The Apex Predator. TLS Online. May 4. Available online: https://www.the-tls. co.uk/articles/public/shakespeare-apex-predator/ (accessed on 1 February 2019).

Strauss, Valerie. 2015. Teacher: Why I Don't Want to Assign Shakespeare Anymore (Even Though He's in the Common Core). Washington Post. June 13. Available online: https://www.washingtonpost.com/news/ answer-sheet/wp/2015/06/13/teacher-why-i-dont-want-to-assign-shakespeare-anymore-even-thoughhes-in-the-common-core/??noredirect=on (accessed on 1 February 2019).

Veletsianos, George, Shandell Houlden, Jaigris Hodson, and Chandell Gosse. 2018. Women Scholars' Experiences with Online Harassment and Abuse: Self-Protection, Resistance, Acceptance, and Self-Blame. New Media $\mathcal{E}$ Society 20: 4689-708.

Vint, Sherryl. 2007. Bodies of Tomorrow: Technology, Subjectivity, Science Fiction. Toronto: University of Toronto Press. 